Elzat AYRAT, Master ${ }^{1}$

(Corresponding author)

E-mail:19120745@bjtu.edu.cn

Xiaoyan LIN, Ph.D. ${ }^{1}$

E-mail: xylin@bjtu.edu.cn

${ }^{1}$ School of Economics and Management

Beijing Jiaotong University

$3^{\text {rd }}$ Shangyuancun Road, Haidian District

Beijing, 100044, China
Transport Economics Original Scientific Paper Submitted: 8 Feb. 2021 Accepted: 31 May 2021

\title{
IS CONGESTION PRICING EFFECTIVE FOR TRAFFIC JAMS?
}

\begin{abstract}
The complexity of urban congestion requires policymakers to adopt different congestion control measures that suit the characteristics of the city at the proper time. The paper focuses on the most controversial congestion pricing and offers methods to judge the efficacy of the policy by game theoretic approaches. It is found that congestion pricing is not merely a Pigouvian tax that internalizes drivers' externalities, but also a powerful means to enhance public traffic proportion and balance road utilization on the premise of maximized social utility. Meanwhile, the embedded multiple case study shows that theoretical correctness of the policy is a necessary, but not sufficient condition for its effectiveness because the valid operation of the policy further requires cities to hold certain attributes in some aspects, such as economic level, population density, proper pricing mechanism, and the ability to limit access to and from certain areas. Moreover, the authority should pay attention to matching the policy goal and its functions for successful implementation.
\end{abstract}

\section{KEYWORDS}

congestion pricing; urban congestion; game theory; social utility; path dependence.

\section{INTRODUCTION}

In urban traffic, road congestion has been recognized as an unsettled issue in many cities around the world. Thus, a series of methods has been put into force to minimize the negative effects from urban congestion. For example, some Chinese cities not only use a lottery system or quotas to limit the vehicle registrations each year, but also discourage private car travelling by requiring all private automobiles to stay off roads one day a week or raising parking fees significantly in the metropolitan area. Besides, some developed economies used envi- ronmental taxes in order to minimize the harmful impact from road congestions [1]. However, not all measures achieved significant success in this battle. Corresponding to the data from the Beijing Transport Institute, although the congestion level slightly decreased since 2007, Beijing is still suffering from congestion problems to some extent (see Figurel).

In addition to disciplinary restrictions on car owners, congestion pricing could be another practical remedy for urban congestion and had some success in cities such as Singapore, London, and Stockholm. Actually, charging for the use of public infrastructure is not a unique concept. It was originally put into practice to inhibit electricity usage during peak hours in the 1970s in order to pull through the energy crisis. Similarly to electric power, urban roads are also scarce resources that should be priced by imposing costs on users [2]. Congestion pricing is generally believed to be a force to make people evaluate their travelling patterns, which means car owners should have to pay more for travelling in rush hours just like people usually do so for airline tickets or hotel rooms during high demand. Thus, road pricing is an intelligent measure to address the problem of urban congestion superficially.

However, congestion pricing is not guaranteed to be efficient for all types of cities, as there are some specific attributes that the city should have in order to make better utilization of road charging. For example, the ability to limit access to and from areas is one of the necessary criteria for the feasibility of the policy. Singapore indeed shows ability because access to the Central Business District (CBD) initially had 33 specific entrance points [3]. Similarly, Stockholm is also suitable for road pricing because the city is built on islands and only 18 access points 


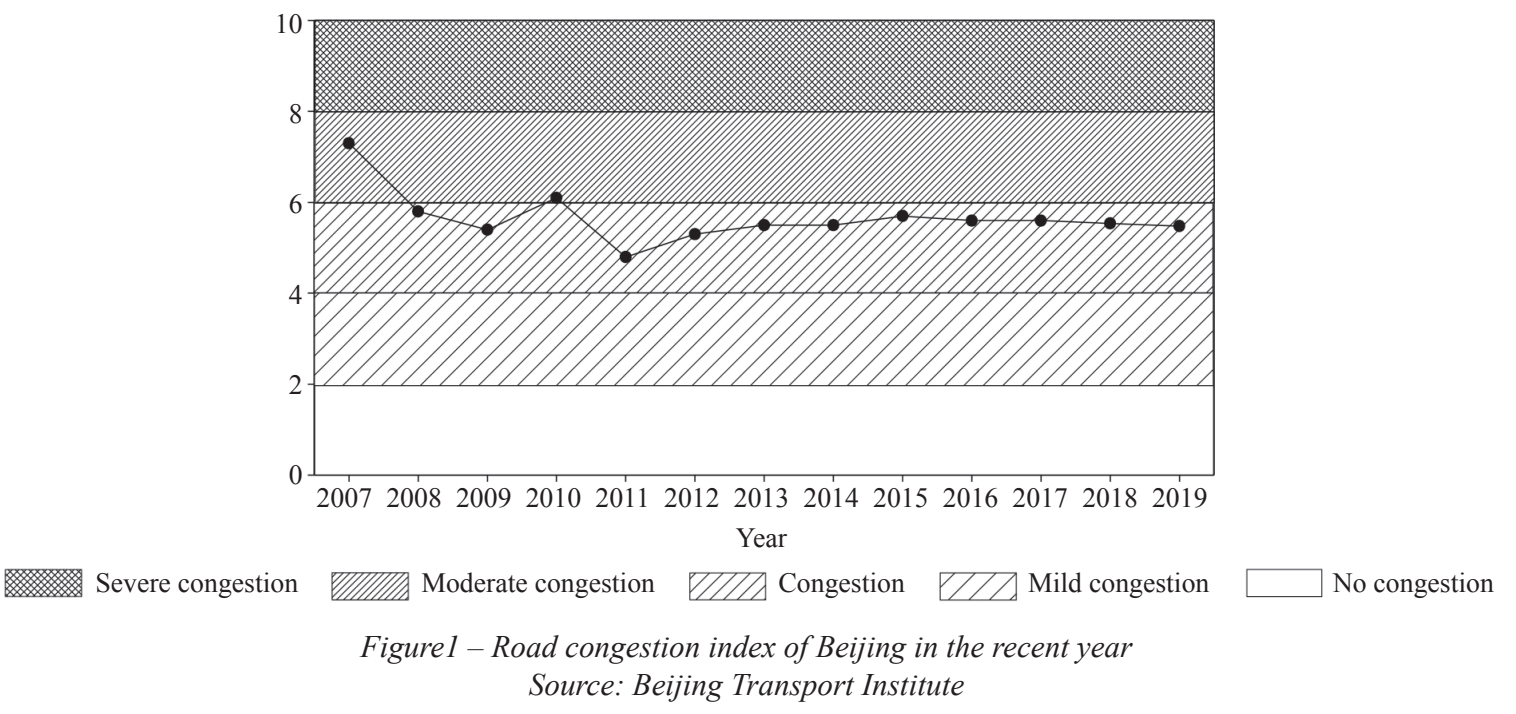

suffice to form a cordon [4]. Besides, although the physical areas of London differ greatly from those of the former two cities, the street network in the core area has hardly been expanded since the medieval ages, which means London also has the ability to limit access [5]. Thus, as for specific cities that satisfy the mentioned conditions, congestion pricing does become an effective measure.

Despite the benefits of the policy, there are still some controversial debates due to the concerns about social response, high initial costs, difficulty in planning of the restricted zones [6], or even undesirable distribution effects of the congestion tolls [7]. In order to demonstrate the efficacy of congestion pricing, the paper fully introduces the principle and practical functions of the policy with convincing theoretical tools. Based on this, by looking through the successful experience of several cities, we explained the importance of matching the applicability and implementation goal of the policy in judging the efficacy of congestion pricing.

\section{THEORETICAL FRAMEWORK}

Theoretical basis of congestion pricing was established in the last century. First, Pigou [8] put forward the idea of congestion charging in his work the Economics of Welfare, followed by the research of Knight [9] arguing that a small tax on large trucks driving on narrow roads could effectively reduce the number of trucks and achieve a benign balance of roads. Since then, as the problem of traffic congestion has become prominent in various states, scholars have conducted in-depth studies on this issue and preliminarily discussed pricing issues. Walters [10] analysed the traffic congestion on American highways and proposed to collect "fuel tax", "city mileage tax" and other special charges. Sharp [11] suggested that the purpose of traffic congestion tax is to realize the rational use of road space and offered a method for pricing based on the principle of marginal cost. Emmerink [12] analysed congestion charging from a neutral standpoint and proposed the advantages and disadvantages of the system by reviewing relevant literature.

On the other hand, as an analytical tool, game theory is often used to illustrate strategic interaction among players who are eager to maximize their own utilities in a specific situation where the actions are available to the players and their utilities are the functions of actions [13]. In certain sophisticated issues, game theory helps to simplify the interaction among different players by analysing the conditions for reaching an equilibrium, more specifically, a Nash equilibrium in many situations. Besides, there are some proven theoretical models that are constructive in explaining the procedure more clearly, such as the Prisoner's Dilemma, Braess Paradox, Entry Game, or Stackelberg Game.

When analysing congestion pricing, game theoretic approaches are also commonly used to explain its inner mechanism. David [14] analysed the interactions of two or more vehicles using game theory and believes that congestion pricing can minimize the total cost of car owners in a cooperation mechanism. Ohazulike et al. [15] used classical game theoretical solution concepts to analyse the action of multi-stakeholders in road pricing game, and found that only under bound restrictions may the game exist in Nash equilibrium. Xiao et al. [16] considered road pricing by combing game theory and congestion theory, and believed that the players' action converges to a Nash 


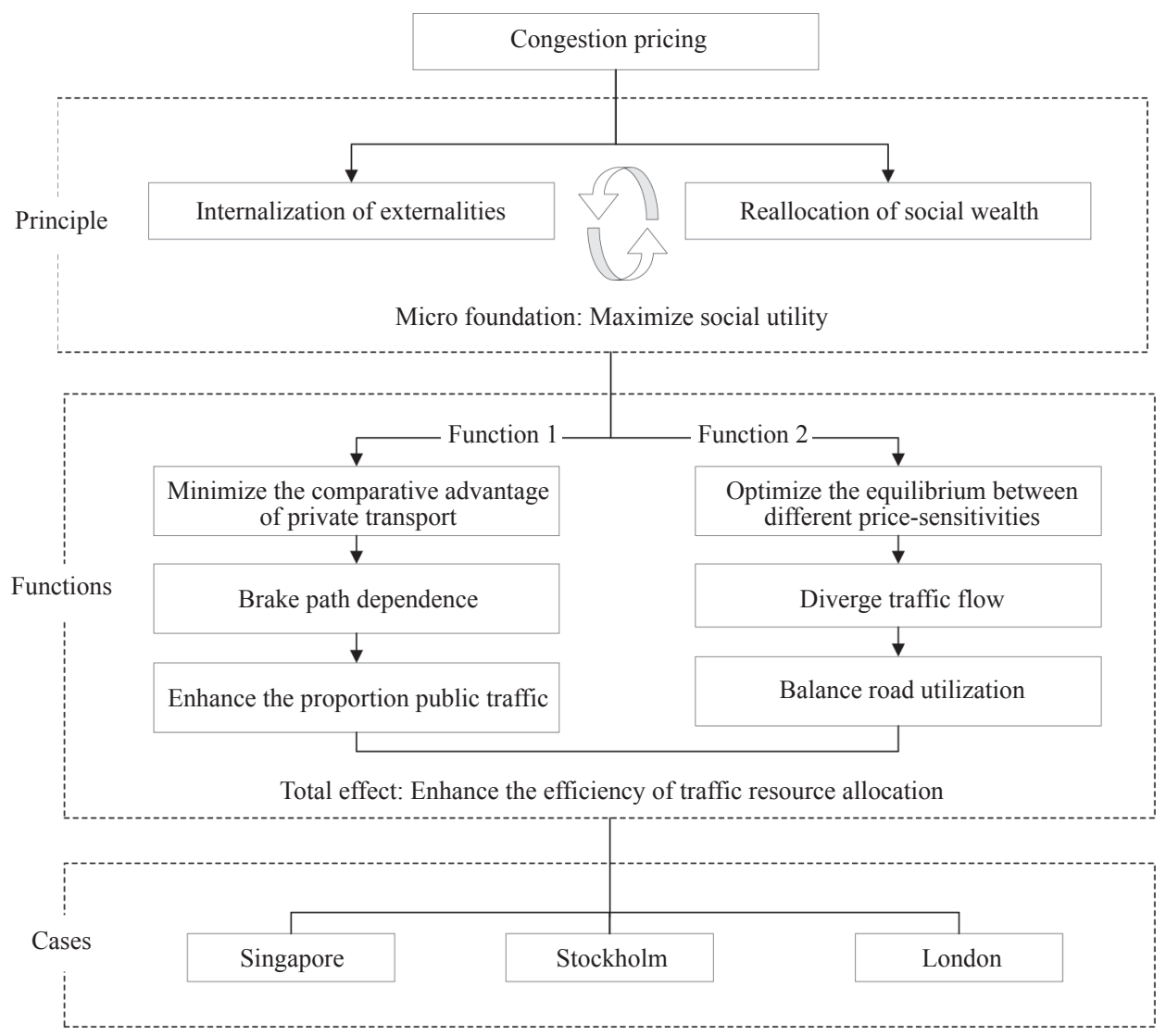

Figure 2 - The theoretical framework of the paper

equilibrium in a congestion game, then concluded that congestion pricing helps to achieve optimal trip timing in local areas. Staňková and Boudewijn [17] believed that the Inverse Stackelberg Game is more adaptable to analyse road pricing, and found that congestion toll can improve the system performance remarkably. Heller et al. [18] offered a new structure using the value of time to improve efficiency of congestion pricing and found a solution based on the Vickery-Clarke-Groves mechanism in game theory to ensure the effectiveness of the policy.

Although researchers conducted a full assessment of the feasibility of congestion pricing $[19,20]$, there is still lack of research regarding its principle and the functional role of the policy by means of convincing theoretical methods. Thus, the paper not only reveals the working mechanism of road pricing but also shows the basic roles thereof with game theoretic approaches. The theoretical framework of the paper is shown in Figure 2.

In the following section, we first present the principle of congestion pricing. More specifically, the general explanation of congestion pricing often keeps to the point where road charging is an appropriate tool to make car owners realize the externalities of their drive, and it further helps government to reallocate social wealth among various aspects in urban traffic. Based on the viewpoint, this paper will analyse the micro-foundation of the policy and explain how a proper amount of congestion tax can maximize the social utility with the use of Stackelberg game.

In the second step, the practical functions of congestion pricing will be introduced by typical game theoretic approaches in order to explain how congestion pricing can alter the traffic pattern to solve the urban congestion problem. Finally, some typical cases of congestion pricing will be demonstrated to clarify the practicality of the policy and further crosscase analysis will be conducted as well.

\section{THE PRINCIPLE OF CONGESTION PRICING}

\subsection{General interpretation}

In neoclassical economics, the working mechanism of congestion pricing is generally interpreted from the perspective of travel cost [21]. When people drive, they only pay attention to how much it costs them to commute due to individual rationality, in which the costs not only include the total vehicle 
purchase cost, fuel cost, and other related taxes, but also cover the cost of travel time. However, car owners do not realize that they ignored other costs generated by the externalities of their travel, such as slowing down the traffic or air pollution. Thus, the traffic flow in a specific road when it reaches equilibrium often exceeds the optimal social level, which means traffic jams occur. The procedure is described in detail below.

The traffic volume is $V$ and the individual travelling cost is $C(V)$. From the point of view of the entire society, the total cost of communicating also includes the cost coming from the externalities $\left(C_{E}\right)$, thus let total travel cost be $T C(V)$, and the marginal social cost $\operatorname{MSC}(V)$ can be denoted as [3],

$$
\begin{aligned}
& M S C(V)=\frac{\partial T V(V)}{\partial V}=C(V)+V \cdot \frac{\partial C(V)}{\partial V} \\
& =C(V)+C_{E}
\end{aligned}
$$

Then, if the two cost lines, $\operatorname{MSC}(V)$ and $C(V)$, respectively cross with the demand curve that implies marginal willingness to pay of all car owners, the efficient equilibrium traffic flow can be found at point $\mathrm{D}$, while the actual equilibrium is found at point $\mathrm{G}$, which means the actual traffic flow exceeds the socially optimal level (see Figure 3). Besides, since the cost in point $\mathrm{G}$ does not include the marginal cost form externalities, the distance between $\mathrm{F}$ and $\mathrm{G}$ represents $C_{E}$. Meanwhile, this leads to a loss in the area of DFG from road congestion. Thus, to prevent the tragedy, government could impose a specific amount of congestion tax, which can be represented as the distance from $\mathrm{C}$ and $\mathrm{D}$. In this way, the actual traffic volume could go back to the social optimal level, and the government can also gain a certain amount of revenue implied by the rectangle $\mathrm{ABCD}$ by collecting the toll that can be used as a financial support for extending or maintaining public transport.

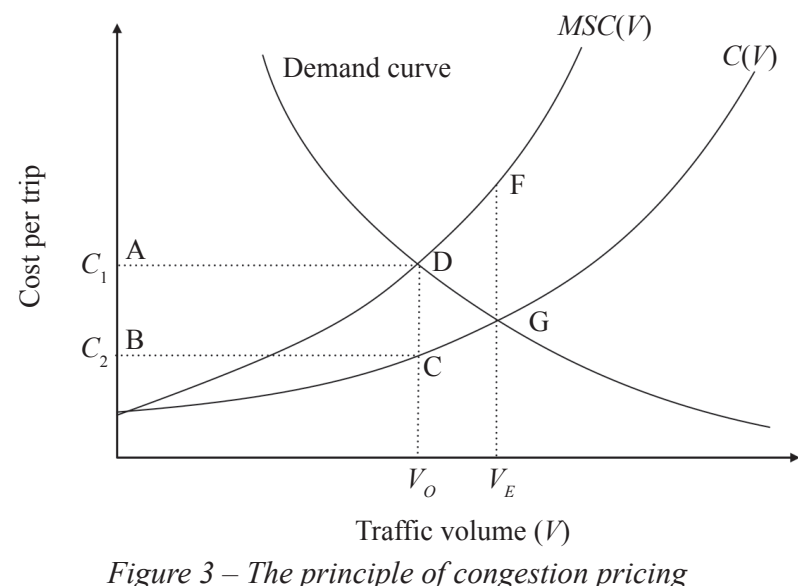

In short, congestion pricing is widely recognized as a kind Pigouvian tax imposed on car owners, which means the policy can fully make people become aware of the externalities of their commute. More specifically, congestion pricing can be generally explained as a signal or information that affects the behaviours of vehicle owners [22] by altering their travel cost. However, although the macroscopic result of the congestion pricing can superficially be explained as above, in order to further recognize the policy more clearly, it is vital to become familiar with its micro foundations [23].

\subsection{Micro foundations}

The micro foundations of congestion pricing can be analysed from the perspective of the stakeholders' utility. Since the government is the overall planner of the congestion pricing, its policy preferences can directly affect travel choices of vehicles. Thus, it is necessary to definite the policy aim of the road authority first. Joksimovic et al. [24] analysed road pricing issues from a game-theoretic perspective and pointed out that different objectives of the road manager could lead to various outcomes. Although the road authority may have different aims in terms of charging, we assume that the primary purpose of the government in congestion pricing is to maximize social utility.

In congestion pricing, social utility is the sum of total charging revenues of the government and total travel utility of vehicles. Therefore, the total charging revenues can be described as follows:

$\mathrm{A}(\lambda)=\sum_{r} q_{r} \cdot \lambda_{r}$

where $q_{r}$ denotes the number of vehicles travelling along road $r$, and $\lambda_{r}$ refers to toll cost of road $r$. Besides, in order to estimate the vehicles' travel utility, we should understand it in a micro prospective, because not only toll costs deduct travel utility, but so do the travel-time costs. Thus, we shall get the following Equations 3 and 4,

$U_{i}=\bar{U}-\mu \tau_{r}-\lambda_{r}$

$B(\lambda)=\sum_{i} U_{i}\left[s_{i}(\lambda) s_{-i}(\lambda), \lambda\right]$

where $U$ represents travel utility of vehicles, in which $\bar{U}$ denotes fixed utility for making the trip, while the travel-time costs $\mu \tau_{r}$ (note: $\mu$ denotes value of time, which converts travel time of $\tau_{r}$ into monetary costs) and toll costs $\lambda_{r}$ decrease the fixed utility. Besides, the total net travel utility would be 
controlled by toll cost planned by the road authority, so $s_{i}(\lambda)$ denotes a strategy set of vehicles $i$, and $s_{-i}(\lambda)$ a strategy set of all other vehicles. Therefore, social utility $W$ can be expressed as follows:

$$
W[s(\lambda), \lambda]=A(\lambda)+B(\lambda)
$$

In practice, the congestion pricing is very similar to a typical game-theoretic model - Stackelberg game, which is a kind of non-cooperative game, in which the "leader" moves first and all the "followers" move after him. So, the leader must take care of the followers' reaction before deciding his strategy. The government is the "leader" who can control the toll cost and the vehicles are the "followers" who should decide their strategy according to government control. Besides, the authority normally has the complete information of registered cars, so we can assume that the government's optimal strategy $\lambda^{*}$ belongs to its strategy set $\Lambda$, as well as the followers' optimal strategy's ${ }^{*}(\lambda) \in S(\lambda)$,

$$
\lambda^{*}=\arg \max _{\lambda \in \Lambda} W\left[s^{*}(\lambda), \lambda\right]
$$

where

$$
s^{*}(\lambda)=\arg \max _{s_{i} \in S_{i}} U_{i}\left[s_{i}(\lambda), s_{-i}^{*}(\lambda), \lambda\right]
$$

In order to clarify the fact, let us do a simple experiment with specific numbers (Note: The numbers are assumed because their absolute would not affect the final direction of the conclusion). We assume there are three strategies for two independent vehicles: traveling on tolled road, travelling on untolled road, or not traveling at all; and their strategy set is $S_{I}=\{1,2,0\}$. Besides, to simplify the experiment, vehicles have the same fixed initial utility $(\bar{U}=310)$ and the same value of time $(\bar{\mu}=8)$. Travel time for different roads is given in Equations 8 and 9.

Based on the experimental number and Equation 5, the utility pay-off can be seen in Table 1:
In the Stackelberg game between the government and vehicles, the 'leader' has the priority to decide its strategy set at first, then the 'followers' get their optimal options. According to Table 1, we can easily find three thresholds for the government strategy set $\{0,16,190\}$. In other words, if the toll cost $\lambda$ ranges between 0 and 16 , the vehicle would choose to travel on the tolled road; in these circumstances, $U_{1}\left(s_{1}^{*}\right)=U_{2}\left(s_{2}^{*}\right)=86-\lambda, A\left(\lambda^{*}\right)=2 \lambda$, and the social utility $W(\lambda)=U_{1}\left(s_{1}^{*}\right)+U_{2}\left(s_{2}^{*}\right)+A\left(\lambda^{*}\right)=172$. Similarly, if $12<\lambda \leq 190$, then vehicles choose different roads to travel, and $U_{1}\left(s_{1}^{*}\right)=\{190-\lambda, 70\}, U_{2}\left(s_{2}^{*}\right)=\{70,190-\lambda\}$, $A\left(\lambda^{*}\right)=\lambda, \quad W(\lambda)=U_{1}\left(s_{1}^{*}\right)+U_{2}\left(s_{2}^{*}\right)+\lambda=260$. If $\lambda \geq 190$, vehicles would prefer to travel on untolled road or not to travel at all, and the social utility $W(\lambda)=U_{1}\left(s_{1}^{*}\right)+U_{2}\left(s_{2}^{*}\right)=70$. Therefore, the government's optimal strategy set is $16 \leq \lambda^{*} \leq 190$, and the maximized social utility is 260 . The analysis above is illustrated in Figure 4.

From the explanation of micro foundation, it can be concluded that congestion pricing can not only be regarded as a kind of Pigouvian tax that makes car owners realize their commute externalities, which



Figure 4 - Social utility in different toll costs

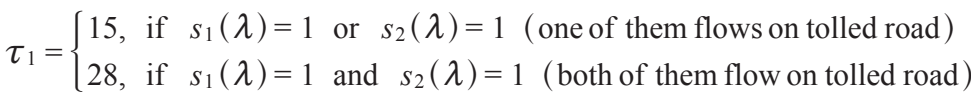

$\tau_{2}=\left\{\begin{array}{lll}30, & \text { if } s_{1}(\lambda)=2 \text { or } s_{2}(\lambda)=2 \quad \text { (one of them flows on untolled road) } \\ 50, & \text { if } s_{1}(\lambda)=2 \text { and } s_{2}(\lambda)=2 \quad(\text { both of them flow on untolled road) }\end{array}\right.$

\begin{tabular}{|c|c|c|c|c|}
\hline & & \multicolumn{3}{|c|}{ Vehicle 2} \\
\hline & & Tolled road & Untolled road & Not travelling \\
\hline \multirow{3}{*}{ Vehicle 1} & Tolled road & $86-\lambda, 86-\lambda$ & $190-\lambda, 70$ & $190-\lambda, 0$ \\
\hline & Untolled road & $70,190-\lambda$ & $-90,-90$ & 70,0 \\
\hline & Not traveling & $0,190-\lambda$ & 0,70 & 0,0 \\
\hline
\end{tabular}

Table 1 - Utility pay-off table for two vehicles 
would further affect the travel patterns of private cars, but can also be an effective tool to achieve the result of maximized social utility by presenting collective rationality, which can relieve congestion in urban traffic. However, it is vital to conduct deeper research to determine proper toll cost for government, otherwise improper pricing could in turn reduce social utility.

\section{THE PRACTICAL FUNCTIONS OF CONGESTION PRICING}

After explaining the principle of road pricing, it is necessary to determine the practical functions of the policy, and meanwhile clarify the inner working mechanism, i.e., what would happen after the traffic patterns changed under congestion pricing.

\subsection{Break the path dependence}

The imbalance between public and private transport is one of the major causes of urban congestion, more specifically, the low utilization rate of public transport is becoming a significant origin of road congestion. After the Industrial Revolution, the urban traffic structure saw a trend of privatization, which is not only due to the convenience of private traffic tools in point-to-point commute, but also due to the government's encouragement because vehicle consumption is a significant stimulation for economy. For example, the development of automobile industry in Britain reached its peak at the beginning of $20^{\text {th }}$ century with 99 automobile factories, whereas this number dropped to 35 in the latter half of the $20^{\text {th }}$ century. A similar situation occurred in countries like France, Germany, and the US [25]. These circumstances are now recurring in developing economies. In China, the accelerated development of automobile industry has led to a substantial increase of private cars at the beginning of this century.

Unfortunately, evidence from practice proves that a large proportion of private vehicles leads to excessive traffic flow in rush hours and could severely affect urban traffic efficiency. Travellers' reliance on private traffic is hard to change because of the "path dependence" formed by the people's travel habit. According to a case study on transit development in Los Angeles, the over-investment of the government on interstates in the last century formed people's preference and dependence on automobiles, which was hard to alter because of the "path dependence", thus it has taken Los Angeles' public transport from prosperity in the 1940s to decline, and received a "reputation" of a congested city [26]. Thus, in order to realize the transformation from public transport to private transport, the key point is to break the "path dependence" with external forces.

In an ideal city land traffic, it is better to have a high proportion of public vehicles in order to maintain good order with no congestion issues, thus public transport can be seen as 'incumbent' in city traffic. However, as it is impossible to achieve satisfaction with buses or trolley buses of every traveller, some citizens buy private vehicles to meet their personalized needs. Therefore, public vehicles can be regarded as 'challengers'. The greater proportion of the 'challengers', the greater possibility of road congestion. Now we shall discuss the process described above by the entry game model, and explain the fact that congestion pricing has a role in fixing the negative process between the 'incumbent' and 'challengers'.

First, we define an entry game $\Gamma$ without congestion pricing by an extensive form game [27]:

$$
\begin{aligned}
& \Gamma=\left\langle N,\left(A_{i}\right), H, P,\left(I_{i}\right),\left(u_{i}\right)\right\rangle \\
& \text { where, }\left\{\begin{array}{l}
N=\{\text { challenger }, \text { incumbent }\} \\
A_{\text {challenger }}=\{\text { in }, \text { out }\} ; A_{\text {incumbent }}=\{\text { accept }, \text { fight }\} \\
H=\{(\text { in }, \text { accept }),(\text { in }, \text { fight }),(\text { out })\} \\
I_{\text {challenger }}=\{\{\varepsilon\}\} ; I_{\text {incumbent }}=\{\{\text { in }\}\} \\
P(\varepsilon)=\text { challenger } ; P(\text { in })=\text { incumbent }
\end{array}\right.
\end{aligned}
$$

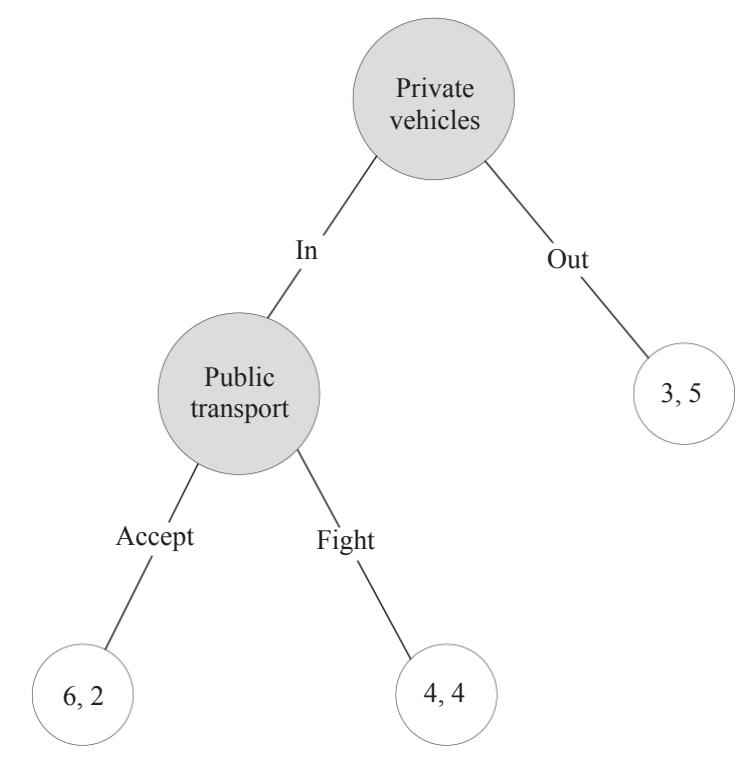

Figure 5 - Entry game between private vehicles and public transport without congestion pricing 
Similarly, in order to make the process clearer, we did an experiment with specific numbers. The assumed utility $u_{i}$ is given in Figure 5 .

In this game, we assume that the social traffic need is equal to 8 . When travellers decide to buy private vehicles to give up their travelling habit by bus or trolleybus, if public transport department chooses not to take action, the number of private cars would increase, and their utility would rise to 6 , while the utility of public transport would be reduced to 2; if the public transport decided to 'fight', the public transport authority would gain investment on public vehicles or apply to the government for some restriction policies against car owners, but the transport supply of the public traffic cannot reach the level where the 'challenger' chose an 'out' in the first place. Thus, the more effective solution is to avoid the entrance of the 'challenger' by making a higher barrier for private vehicles and simultaneously give support to public traffic in order to improve service quality.

Figure 6 illustrates the transformation in the entry game after congestion pricing. More specifically, private vehicles can be taxed in two units if they choose to be "in" the game; meanwhile, the taxes collected can be subsidized for public traffic. Compared to Figure 5, the Nash equilibrium in the game has changed from $\{$ in, fight $\}->(4,4)$ to the new equilibrium \{out, fight\} $>(3,5)$. Although the 'incumbent' need not 'fight' as the 'challenger' would choose an 'out', it can be understood as a threat of public transport to the private vehicles. Thus, the original

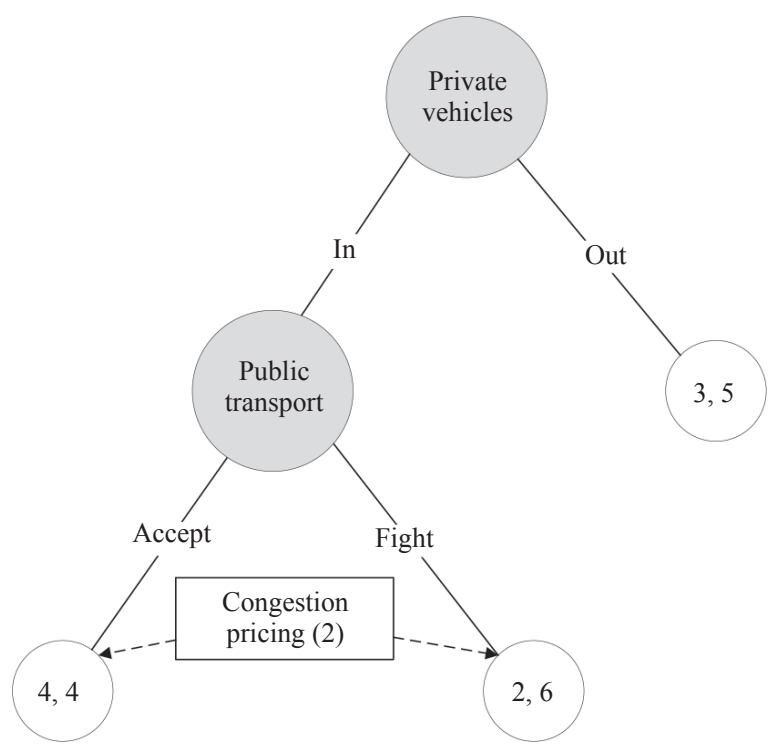

Figure 6-Entry game between private vehicles and public transport after congestion pricing goal of avoiding the entrance of the 'challenger' was achieved, and the public traffic enjoys financial support thanks to the congestion pricing as well.

The game illustrates that the congestion pricing is an external force to break the "path dependence" of people's reliance on private traffic by minimizing the comparative advantage of private cars to public transport as the policy can realize the reallocation of traffic payoff from private traffic to public transport. Thus, congestion pricing is an effective way to guide the transfer of private transport to public traffic, which can relieve the urban road congestion.

\subsection{Diverge the traffic flow}

Except for the proper relations between public and private transport, the balanced utilization of existing urban roads is another guarantee of traffic efficiency, which is more useful in prevention of congestion comparing to investing in new routes. In the Fundamental Law of Highway Congestion, which is also known as Downs Law in transportation economy, it is believed that increased provision of urban roads is unlikely to relieve road congestion without effective government regulations [28]. However, today's aim of urban traffic planning is more likely to concentrate on new construction rather than balance utilization of traffic roads, so this phenomenon can be another reason for urban congestion.

In game theory, the Braess Paradox Game also illustrates the same principle that a transportation network with extra capacity added may actually perform worse than without extra capacity [29]. We assumed a network consists of a starting point $\mathrm{S}$ and a finishing point $\mathrm{F}$, and two workable paths are denoted as P1 and P2 (as Figure 7a). The travel utility of routes is expressed as follows: route $\{\mathrm{S}->\mathrm{P} 2\}$ and $\{\mathrm{P} 1->\mathrm{F}\}$ have a fixed cost of -25 , while the utility of the two other paths depends on the number of vehicles, and satisfies cost $c=-N / 50 \quad(N=1000)$. Thus, it is very clear that vehicles would naturally divert to two different paths in order to achieve the minimized cost $c_{\min }=-25-500 / 50=-35$. However, in order to relieve traffic burden of the existing roads, if the government decides to invest in a new road (without any travel cost) between P1 and P2 instead of opting for other measures (see Figure 7b), the situation can only get worse: all vehicles will choose the path $\{\mathrm{S}->\mathrm{P} 1->\mathrm{P} 2->\mathrm{F}\}$ in order to minimize their travel costs, but the "minimum cost" would rise to $c_{\min }=-1000 / 50-1000 / 50=-40$, and would conversely increase the traffic burden of the two existing roads. 


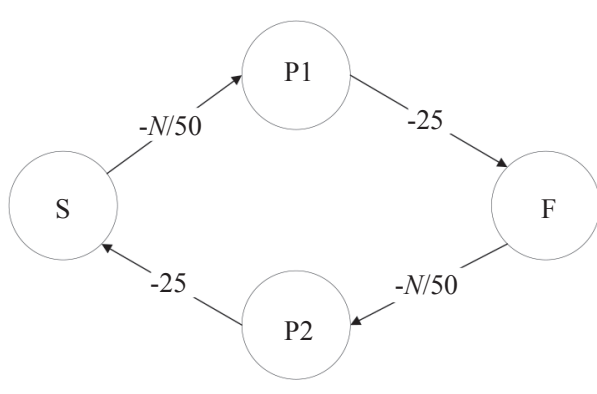

a)

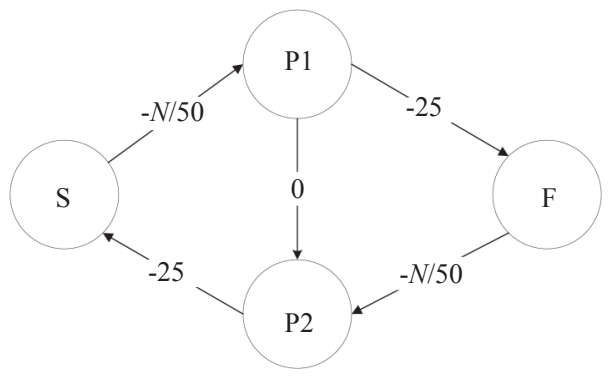

b)

Figure 7 - Diagram of the Braess Paradox Game

Therefore, in order to relieve road congestion, it is wise to take measures to diverge traffic flow and achieve a balanced utilization of urban traffic roads rather than investing in new ones. Now, let us consider the congestion pricing. Even though the same amount of congestion tax is imposed to all travellers, they may have different reactions to the policy because of their wage levels, travel motivation, and the need for convenience. The differences in price sensitivity contribute to highlighting another role of congestion pricing - traffic diversion.

Normally, the urban road system can be divided into arterial roads and non-arterial roads. With no restrictions, more vehicles choose arterial roads because of many advantages, such as higher driving speed, better experience, or border view, which lead to excessive traffic flow or even road congestion, while the utilization efficiency of non-arterial roads becomes relatively low. If the procedure is analysed in game theory, it can be found that it is very similar to a typical issue - the prisoners' dilemma. In order to clarify the fact, the issue can also be expressed by simple numerical experiment. First, we define a strategy form game $\Gamma$ :

$\Gamma=\left\langle N,\left(S_{i}\right),\left(u_{i}\right)\right\rangle$

where, $\left\{\begin{array}{l}N=\{\text { price }- \text { sensitives, } \text { non }- \text { price }- \text { sensitives }\} \\ s_{i}=\{\text { trunkrodes, }, \text { non } \text {-trunkrodes }\}\end{array}\right.$

Then, the utility pay-off table of players without congestion pricing is assumed in Table 2. More specifically, as for travellers' preferences for arterial roads, the total utility of arterial roads is given 10 points, while the non-arterial roads' utility is 6 .
However, in the circumstance of scattered traffic flows, an individual's utility shall improve, thus other numbers are allocated as below.

In this game, the strategy of 'arterial roads' is strongly dominated by the strategy of 'non-arterial roads' for price-sensitives, namely:

$\left\{\begin{array}{l}u_{\text {price-sensitives }}(A, N A)>u_{\text {price-sensitives }}(N A, N A) \\ u_{\text {price-sensitives }}(A, A)>u_{\text {price-sensitives }}(N A, A)\end{array}\right\}$

Similarly, in terms of non-price-sensitives, the strategy of 'arterial roads' is also strongly dominated by the strategy of 'non-arterial roads':



Thus, the strategy set $s^{*}=\{$ arterial roads, arterial roads $\}$ can satisfy Equation 16. In other words, the pure Nash equilibrium among the players is if both choose the arterial roads. However, the equilibrium cannot reach the goal of traffic diversion and can even lead to road congestion. Thus, without road pricing, a kind of multiplayer prisoner's dilemma would easily arise.

$u_{i}\left(s_{i}^{*}, s_{-i}^{*}\right)=\max _{s_{i} \in S_{i}} u_{i}\left(s_{i}, s_{-i}^{*}\right), \quad \forall i=1,2$

Just imagine the circumstance where all vehicles were imposed four units of congestion tax if they chose arterial roads: the Nash equilibrium would change, and the new pay-off table is showed in Table 3. Since the two types of travellers have different price-sensitivity, vehicles would react differently to the road congestion policy. More precisely, the travel utility of price-sensitives would decrease when choosing the arterial roads, while the other

Table 2 - The utility pay-off table of players without congestion pricing

\begin{tabular}{||c|c|c|c|}
\hline \multirow{2}{*}{\multicolumn{2}{|c|}{}} & \multicolumn{2}{|c|}{ Non-price-sensitives } \\
\cline { 3 - 4 } \multicolumn{2}{|c|}{} & Arterial roads (A) & Non-arterial roads (NA) \\
\hline \hline \multirow{2}{*}{ Price-sensitives } & Arterial roads (A) & 5,5 & 6,4 \\
\cline { 2 - 4 } & Non-arterial roads (NA) & 4,6 & 3,3 \\
\hline
\end{tabular}


Ayrat E, Lin X. Is Congestion Pricing Effective for Traffic Jams?

Table 3 - The utility pay-off table of players with congestion pricing

\begin{tabular}{|c|c|c|c|}
\hline & & \multicolumn{2}{|c|}{ Non-price-sensitives } \\
\hline & & Arterial roads (A) & Non-arterial roads (NA) \\
\hline \multirow{2}{*}{ Price-sensitives } & Arterial roads (A) & 1,5 & 2,4 \\
\hline & Non-arterial roads (NA) & 4,6 & 3,3 \\
\hline
\end{tabular}

type of travellers would believe that a small amount of congestion tax is insignificant compared to their travel intension as to change their travel path. Thus, according to Table 3 and Equation 16, we would find the new Nash equilibria are $\{\mathrm{A}, \mathrm{NA}\}->(2,4)$ and $\{\mathrm{NA}, \mathrm{A}\}->(4,6)$, and the subgame-perfect equilibrium is the latter one. Therefore, the aim of traffic diversion can be accomplished, which is beneficial for balanced utilization of urban traffic roads.

In addition, the ratio between price-sensitives and non-price-sensitives is not very vital. Traffic is a nonlinear concept, and as some owners leave, the traffic flow on the major roads drops dramatically [30]. For example, even though only $20 \%$ of car owners in a city belong to price-sensitives and change their path choice due to congestion pricing, the traffic flows on congested roads will drop much more than $20 \%$ because of the inner mechanism of the traffic system. Thus, another role of congestion pricing is to realize traffic diversion by fixing the prisoners' dilemma between car owners with different price sensitivity, whereby the imperfection in balanced utilization of urban traffic roads is supposed to decrease, which would be beneficial for the road congestion problem.

Congestion pricing should be considered an effective tool to allocate a limited traffic resource by modifying travellers' behaviours in terms of route choice or by managing the road space [31]. In this part, the process demonstrated that congestion pricing not only helps to enhance the proportion of public traffic by breaking the path dependence but also balances the utilization of urban roads by diverging the traffic flow, which finally promotes the efficiency of traffic resource allocation.

\section{MULTIPLE CASE STUDY}

Having introduced the basic principle and practical function of congestion pricing, the major purpose of this part is to figure out the applicability of this policy in actual conditions by demonstrating the cases. The perspective of some policy makers is that the application of congestion pricing on the road network of certain cities depends on primary attributes of the city rather than on mere drivers' behaviour. Therefore, based on previous experiences, we will explore the type of cities where congestion pricing would play a significant role as presented in the last part.

\subsection{The case of Singapore}

As one of the Four Asian Dragons, Singapore is a promising country that has realized 2.9 percent of annual economic growth rate from 2014 to 2019 , which is faster than any other leading economy over the same period. GDP per capita reached US\$65,233, which is why it ranked first in the Asian countries. However, it is a city-state country with a population of around 5.69 million, and since it is located on a small island, it has a relatively high population density of about 10,500 persons per square $\mathrm{km}$. The scarcity in territorial area has led to a lot of restrictions on the development of land traffic. For example, the roads constructed already constitute 12 percent of the island's area, which is nearly the same share as the local housing area, so it is hard to expand the road supply. Besides, with the continued rising of personal income, the car ownership has been booming since the middle of last century. As early as in the 1970s, the traffic congestion problem had become one of the main issues in the country.

In order to deal with this obstacle, the government of Singapore begun to take measures very early, and the most effective one was the Area Licensing System (ALS) put forward in 1975, which was the first comprehensive road pricing scheme in the world. The system was designed to dissuade the entry of private passenger cars and taxis into the CBD during the morning peak, and it was instituted manually to collect toll at that time. After a period of operation, the authority found the initial results were far from ideal. For example, the phenomenal reduction in traffic flow led to wasteful underutilization of the roads in restricted areas, and the congestion problem was not eliminated, rather the time and location of the congestion were merely shifted. Moreover, the congestion greatly increased the inconveniency and commute cost of the citizens because they were 
being compelled to take longer distance in order to circumvent the restricted zones and avoid paying the fees [32].

Following many years of trials and extensive preparation, the government of Singapore not only optimized the pricing scheme to avoid any related problems but also achieved a smooth transition from the ALS to Electronic Road Pricing (ERP) in 1998. With the use of ERP, vehicles are charged by gantries without a slowdown, which have antennas that check smart cards on approaching vehicles and then debit the cards. Moreover, the reason why Singapore's ERP scheme achieved splendid success was not the electronic technology itself, because Hong Kong had already engaged in area wide ERP before. Instead, the key point is that Singapore implemented the most comprehensive system of quotas and tolls in the world to curb both the ownership and usage of motor vehicles, which can avoid the related privacy concerns that arose in Hong Kong [33]. Thus, although commuters have kept increasing with the development of economy during early 1980s to late 1990s, the average travel speed during the morning and the evening peek reached 30 kilometres per hour, while other cities like New York achieved only $10 \mathrm{~km} / \mathrm{h}$.

On the other hand, the applicability of congestion pricing in different cities depends on many conditions other than the ones mentioned above. For example, it is much easier for authorities to limit the access to central areas because there are only several entrance points to the restricted zone. In addition, the population of Singapore not only has a relatively high individual income but also comprises a high proportion of obedient law-abiding citizenry. Therefore, the success of Singapore's congestion pricing is attributable to a combination of various factors.

\subsection{The case of London}

As one of the international metropolises, London also has a high level of population density of 5,800 persons per square $\mathrm{km}$. In addition, the street network in central London was nearly kept unchanged since the medieval ages, so the very limited expansion capacity could hardly meet the heavy travel demand after experiencing a boom in the number of vehicles since the 1960s. Thus, central London became another typical city that implemented congestion pricing, which practically put the policy into practice in 2003.
Before the formal implementation, some experts argued that having a relatively good travel alternatives, such as walking, taxi and subway, it was not necessary for London to push citizens to the direction of diverse travel patterns deliberately with the use of external policies [34]. However, with the continuing increase of population and individual income, the ownership of private cars increased with the surplus capacity of public transport, so the authorities found that road pricing might be an effective policy to transfer people from individual vehicles to public transit.

Singapore's success in congestion charging encouraged London to establish a similar charging model of area licensing. However, when it comes to the specific charging amount, London implemented a flat rate rather than a dynamic one. The daily charge between 7:00 a.m. and 6:30 p.m. for private cars was $£ 5$, higher than for commercial vehicles, and it was increased to $£ 8$ in 2005 . In view of social equity objectives, there were certain discounts or exemptions for emergency and government vehicles, or for residents and disabled drivers. On the other hand, a network of video cameras is utilized to record the license plate numbers of vehicles, which is similar to Singapore's ERP scheme, and car owners can make the payments at payment machines and selected retail outlets, or via Internet and text messaging as well [35]. It is worth emphasising here that the basic characteristics of a city, including geographical features, economic level and urban culture, could largely affect the difficulty or feasibility of the implementation of congestion pricing. London Congestion Charge has to cover almost 22 square kilometres, while Singapore's ERP only encompasses 7 square kilometres because of the differences in physical areas [3].

After several years, a series of alternations on urban traffic patterns has indicated that congestion pricing is efficient for the congestion problem in London. First, the traffic flow within the restricted zone was reduced by $15-18$ percent during charging hours, which contributed to the reduction in traffic delays by almost 26 percent. Meanwhile, the travel speed of vehicles in rush hours increased by 37 percent in the charging zone [36]. Besides, the reduction in private vehicles was the major reason for the uptick in the use of public transportation. Based on relevant statistics, the running speed of public transport saw a 21 percent increase, which contributed the use of bus services increasing by 
40 percent [37]. Moreover, some environmental benefits were seen after the implementation. For example, as of 2005, the emissions of PM10 and nitrogen oxides were reduced by almost 12 percent [38], which proved to benefit the extension of life expectancy in the Greater London area.

From the perspective of social utility, both government and citizens became more satisfied during the period. On the one hand, London's government shared the total net benefit of 67 million pounds a year for the first 30 months of the congestion charge [39]. On the other hand, although there was a certain proportion of public scepticism at the initial adoption of congestion pricing in London, it had turned into support after achieving fluent traffic. According to a survey, the acceptability of congestion charging has increased from the initial 40 percent to 55 percent after implementation, and 78 percent of car owners who took part in the survey were satisfied with the system [34]. Thus, with a meticulous organization, congestion pricing could also be widely accepted by car owners.

\subsection{The case of Stockholm}

Stockholm is the capital of Sweden, and it is a medium-sized city with 5,400 square kilometres of urban area, with an urban population of about 800,000 . In terms of per capita land area, the traffic congestion problem of the city should not be serious, but the geographical characteristics of the city prevent benign development of urban traffic. There are 14 islands and a peninsula in downtown Stockholm, and more than 70 bridges were built to connect them. This means that during rush hours, traffic jams often occur at bridge entrances and exits.

Unlike other cities, Stockholm initiated a sixmonth trial period in 2006 to fully observe public reactions to the policy. The authority designed toll points on 18 bridges, important entrances into the city centre, where congestion was the most serious in terms of the entire city, and the vehicles were charged in the time period from $6: 30 \mathrm{a} . \mathrm{m}$. to 6:30 p.m. local time. In addition, in order not to interfere with normal traffic, special registration devices were set up at the toll points, matching the payment system in the car, which automatically deducted money from the owner's credit card. Moreover, the amount of money charged from car owners passing through the toll points varies in different time periods. More specifically, the amount reached 20 kronor in the rush hour and there was no charge during the night when traffic was light. Meanwhile, a maximum of 60 kronor was charged per vehicle per day for the benefit of the car owners [40].

After six months of testing, a team of eight transportation experts analysed the implementation structure and came to some important conclusions [41]. First, there was a steady decline in traffic flow at peak hours, and the largest drop in traffic flow in 24 hours reached 22 percent, which was more significant than the previously expected reduction in traffic flow of $10-15 \%$. Second, with the decrease of traffic flow, the time spent by car owners on the road is significantly reduced, which means the occurrence of congestion in the city has decreased. Third, the use of public transport in Stockholm in the spring of 2006 increased by 6 percent compared with the same period last year, and excluding the reduction in the use of private cars due to rising petrol prices, the remaining reduction of 4.5 percent can be attributed to congestion pricing. Furthermore, although the probability of accidents is uncertain in a city, the reduction of injuries in Stockholm ranged between 9 percent and 18 percent during the trial period, which could be closely related to a decrease in traffic flow thanks to congestion pricing. On the other hand, as the number of private cars travelling has decreased, carbon dioxide emissions from roads have decreased significantly, in which emissions from suburban roads were reduced by 2 percent and those from urban roads by 14 percent.

From the congestion charging trial in Stockholm, it can be concluded that congestion pricing is not only beneficial to evacuate traffic flow in arterial roads and then to promote the reasonable allocation of road resources, but also can improve the utilization rate of public transport so as to effectively reduce the urban congestion probability in terms of small-sized or medium-sized cities like Stockholm. Besides, the policy contributes to improve road safety and reduce traffic pollution emissions as well. Finally, it is worth mentioning that the public support rate reached over 70 percent after the six-month trial, and it was only around 30 percent before the enforcement of congestion pricing, which indicates that people would support this kind of social optimal public policies after realiz- 
ing the advantages of collective rationality. Thus, a permanent congestion charging program was reintroduced in 2007.

\subsection{Cross cases discussion}

Except for the three cases analysed above, congestion pricing had a broad utilization in many cities around the world, such as Anas, Lindsey, Milan, Oslo, Bergen, and Gothenburg [42]. However, just as mentioned in the previous sections, it is hard to say that congestion charging is suitable for all kinds of cities. In other words, some specific attributes do exist in cities that allow for a successful implementation of the policy, which magnifies the applicability of road charging in these cities. Table 4 summarizes the attributes of the cities in the three cases, and estimated attributes of New York and Beijing are also listed for comparison as a control group.

It can be seen in the Table that certain conditions of cities in the control group seem to be very suitable for implementing the policy, but would not be applicable from other points of view. For example, New York City announced to enact congestion pricing in 2019, and may become the first major US city to adopt the policy. Compared to the cities in the case study, although the economic conditions or technical measures would not be the problem, a relatively low population density and extra road expansion capacity could make it hard for policy makers to convince the public that congestion pricing is the best measure. As early as in April 2007, Mayor Michael Bloomberg proposed to implement congestion pricing in New York City, but the state legislature denied the proposal because of their doubt in the societal and individual impact of the policy [43]. In addition, Beijing Municipal Ecology and Environmental Bureau also considered trying to implement a congestion pricing policy in 2013. But during the practical planning process, the authority discovered some bottlenecks, concluding that the lack of pricing and access limitation methods suitable for the attributes of the city should be tackled before real implementation.

Besides, the policy effects also depend on the degree of matching between the practical functions and the implementation objective of the authority. In the last section, we concluded that the major functions of congestion pricing are enhancing the proportion of public traffic and balancing the utilization of urban roads. From the practice of cities in the case study, it can be found that these functions match the policy goals. For example, as for Singapore and Stockholm, the major intention is to better use urban roads in other areas in order to avoid heavy congestion in specific networks. The primary objective of London is to improve utilization of public traffic. Therefore, before the implementation of the policy, in addition to estimating whether a city has the essential attributes for a successful implementation of the policy, the authority should also determine the core issues that induce urban congestion and decide whether congestion pricing is the solution.

Table 4 - The applicability of congestion pricing in different cities

\begin{tabular}{|c|c|c|c|c|c|c|c|c|c|}
\hline \multicolumn{2}{|c|}{ Name and remarks } & $\begin{array}{c}\text { Economic } \\
\text { level per } \\
\text { capita }\end{array}$ & $\begin{array}{c}\text { Population } \\
\text { density }\end{array}$ & $\begin{array}{l}\text { Further } \\
\text { expansion } \\
\text { room for } \\
\text { roads }\end{array}$ & $\begin{array}{c}\text { Growth } \\
\text { rate of car } \\
\text { ownership }\end{array}$ & $\begin{array}{l}\text { Ability } \\
\text { to limit } \\
\text { access to } \\
\text { and from } \\
\text { areas }\end{array}$ & $\begin{array}{l}\text { Ability } \\
\text { to use } \\
\text { electronic } \\
\text { techniques }\end{array}$ & $\begin{array}{l}\text { Proper } \\
\text { pricing } \\
\text { ability }\end{array}$ & $\begin{array}{c}\text { Law- } \\
\text { compliance } \\
\text { level of } \\
\text { citizens }\end{array}$ \\
\hline \multirow{2}{*}{ Singapore } & Applicability & $\sqrt{ }$ & $\sqrt{ }$ & $\sqrt{ }$ & $\sqrt{1}$ & $\sqrt{1}$ & $\sqrt{2}$ & $\sqrt{1}$ & $\sqrt{ }$ \\
\hline & Level & high & high & tiny & high & high & high & high & high \\
\hline \multirow{2}{*}{ London } & Applicability & $\sqrt{ }$ & $\sqrt{ }$ & $\sqrt{ }$ & $\sqrt{ }$ & $\sqrt{ }$ & $\sqrt{ }$ & $\sqrt{ }$ & $\sqrt{ }$ \\
\hline & Level & high & medium & tiny & high & high & high & medium & high \\
\hline \multirow{2}{*}{$\begin{array}{l}\text { Stock- } \\
\text { holm }\end{array}$} & Applicability & $\sqrt{ }$ & $\mathrm{X}^{*}$ & $\sqrt{ }$ & $\sqrt{ }$ & $\sqrt{ }$ & $\sqrt{ }$ & $\sqrt{ }$ & $\sqrt{ }$ \\
\hline & Level & medium & low & tiny & high & high & high & high & high \\
\hline \multirow{2}{*}{ New York } & Applicability & $\sqrt{ }$ & $\mathrm{X}$ & $\mathrm{X}$ & $\sqrt{ }$ & $\mathrm{X}$ & $\sqrt{ }$ & $\mathrm{X}$ & $\mathrm{X}$ \\
\hline & Level & high & low & huge & high & low & high & low & medium \\
\hline \multirow{2}{*}{ Beijing } & Applicability & $\mathrm{X}$ & $\sqrt{ }$ & $\mathrm{X}$ & $\sqrt{ }$ & $\mathrm{X}$ & $\sqrt{ }$ & $\mathrm{X}$ & $\sqrt{ }$ \\
\hline & Level & low & medium & huge & high & low & high & low & high \\
\hline
\end{tabular}

${ }^{*}$ Although the population density of Stockholm does not satisfy the standard, the geographical characteristics of the city make it suitable for congestion pricing. 


\section{CONCLUSION}

In this paper, the effectiveness of congestion pricing is investigated by considering the applicability of the policy in different cities. First, in order to fully grasp the inner mechanisms, the principle of road pricing was introduced as a research basis. Unlike other existing studies, this paper not only demonstrates macroscopic results of policy implementation with traditional neoclassical economic approach from the perspective of travel cost, but the micro-foundation of the policy is further discussed considering social utility. Thereby it is found that congestion pricing can not only be regarded as a kind of Pigouvian tax that makes car owners recognize their commute externalities, but can also be an efficient tool to achieve the outcome of maximized social utility by presenting collective rationality, which can relieve congestion in urban traffic. The importance of accurate pricing is also highlighted, which is one of the key elements of policy efficiency.

The direct purpose of every congestion control policy is to alter traffic pattern in order to change the congested urban traffic. By use of game theoretic tools, such as Prisoner's Dilemma, Braess Paradox, Entry Game and Stackelberg Game, we demonstrated that congestion pricing can not only break the "path dependence" of people's reliance on private traffic by minimizing the comparative advantage of private cars to public transport, but also contribute to a balanced utilization of urban roads by altering the equilibrium among car owners with different price sensitivity. Therefore, the two basic roles of the policy are vital to understand the efficacy of congestion pricing.

Finally, the embedded multiple case study is conducted in order to explain the precondition of application of congestion pricing. In other words, the theoretical correctness of a policy is the necessary but not the sufficient condition for its efficacy. More precisely, a group of cities, such as Singapore, Stockholm, and London, have successfully implemented congestion charging as a remedy for their urban traffic issue, which has proved the efficiency and practicability thereof. Thus, for such cities that possess certain attributes, the participial functions discussed in the last part "worked". However, as for other cities, such as New York or Beijing, it may not be the appropriate time for implementation due to the lack of fundamental attributes or matching degree between practical functions and the imple- mentation goal of the authority. Thus, it is necessary for governments to better understand the policy, and more importantly, to make the right judgment on the appropriate time of implementation.

\section{ACKNOWLEDGMENT}

This study was supported by the major project of the National Social Science Foundation of China (Research on the Analytical Framework and Evolution Path of China's High-Speed Rail Economy) (17ZDA084).

伊力扎提・艾热提, 硕士 ${ }^{1}$

电子邮箱: 19120745@bjtu.edu.cn

林晓言, 博士 ${ }^{1}$

电子邮箱: xylin@bjtu.edu.cn

1 北京交通大学经济管理学院

中国北京市海淀区上园村3号

拥堵定价的有效性一基于博弯论

\section{摘要}

城市拥堵的复杂性要求决策制定者在合适的时 间采取与城市属性相匹配的不同拥堵控制措施。本 文以国际上最具争议的拥堵收费政策为主要研究对 象, 利用博恋论提供了判断拥堵收费政策有效性的 方法。研究发现, 拥堵收费不仅是一种庇古税, 而 是在实现最大化社会效益的情况下，提高公共交通 利用率及道路资源配置效率的有效方法之一。然 而, 多项嵌入式案例研究结果表明, 拥堵收费在理 论上的正确性只是其现实中有效性的必要非充分条 件; 即该政策能够有效运行要求城市本身具备一系 列属性, 譬如经济水平、人口密度、合理的定价机 制以及限制进出区域的能力等。因此, 管理当局只 有注意政策目标与政策作用的匹配性时，才能保证 政策的成功实施。

\section{REFERENCES}

[1] OECD. Tax policy reforms 2018: OECD and selected partner economies. Paris: OECD Publishing; 2018.

[2] Vickrey WS. Pricing in urban and suburban transport. The American Economic Review. 1963;53(2): 452-465. http://www.jstor.org/stable/1823886 [Accessed 2nd June 2021].

[3] RidderZJ. The efficacy of congestion pricing. Honors Theses. 2016;76: 1-46. https://scholar.utc.edu/honors-theses/ 76/ [Accessed 2nd June 2021].

[4] Song S. Should China implement congestion pricing? Chinese Economy. 2015;48(1): 57-67. doi: 10.1080/10971475.2015.993200.

[5] Litman T. London congestion pricing-implications for other cities. CESifo DICE Report. 2005;3(3): 17-21. https://core.ac.uk/download/pdf/6630967.pdf [Accessed 2nd June 2021].

[6] Jakob M, Menendez M. Parking pricing vs. congestion pricing: A macroscopic analysis of their impact on traf- 
fic. Transportmetrica A: Transport Science. 2020;17(4): 1-30. doi: 10.1080/23249935.2020.1797924.

[7] Small KA, Verhoef ET, Lindsey R. The economics of urban transportation. London: Routledge; 2007.

[8] Pigou AC. The economics of welfare. London: Palgrave Macmillan; 2013.

[9] Knight FH. Some fallacies in the interpretation of social cost. The Quarterly Journal of Economics. 1924;38(4): 582-606. doi: 10.2307/1884592.

[10] Walters AA. The theory and measurement of private and social cost of highway congestion. Econometrica. 1961;29(4): 676-699. doi: 10.2307/1911814.

[11] Sharp C. Congestion and welfare-an examination of the case for a congestion tax. The Economic Journal. 1966;76(304): 806-817. doi: 10.2307/2229084.

[12] Emmerink R, Nijkamp P, Rietveld P. Is congestion pricing a first-best strategy in transport policy? A critical review of arguments. Environment and Planning B: Planning and Design. 1995;22(5): 581-602. doi: 10.1068/ B220581.

[13] Lucchetti R. A Primer in Game Theory. Bologna: Società Editrice Esculapio; 2011.

[14] Levinson D. Micro-foundations of congestion and pricing: A game theory perspective. Transportation Research Part A: Policy and Practice. 2005;39(7-9): 691704. doi: 10.1016/J.TRA.2005.02.021.

[15] Ohazulike AESG. Multi-stakeholder road pricing game: solution concepts. International Journal of Computational and Mathematical Sciences. 2012;6: 1-12. https://ris.utwente.nl/ws/files/6398255/v63-3.pdf [Accessed 2nd June 2021].

[16] Xiao N, et al. Road pricing design based on game theory and multi-agent consensus. IEEE/CAA Journal of Automatica Sinica. 2014;1(1): 31-39. doi: 10.1109/ JAS.2014.7004617.

[17] Staňková K, Boudewijn A. Stackelberg and Inverse Stackelberg Road Pricing Games: State of the Art and Future Research. Heidelberg, Germany: Springer; 2015. https://cris.maastrichtuniversity.nl/en/publications/stackelberg-and-inverse-stackelberg-road-pricing-games [Accessed 2nd June 2021].

[18] Heller C, Johnen J, Schmitz S. Congestion pricing: A mechanism design approach. Journal of Transport Economics and Policy. 2019;53(1): 74-98. https:/www.ingentaconnect.com/content/lse/jtep/2019/ 00000053/00000001/art00005 [Accessed 2nd June 2021].

[19] Evans AW. Road congestion pricing: when is it a good policy? Journal of Transport Economics and Policy. 1992;26(3): 213-243. https://www.jstor.org/stable/20052985 [Accessed 2nd June 2021].

[20] Giuliano G. An assessment of the political acceptability of congestion pricing. Transportation. 1992;19(4): 335358. doi: 10.1007/BF01098638.

[21] Santos G. Urban congestion charging: A comparison between London and Singapore. Transport Reviews. 2005;25(5): 511-534. doi: 10.1080/ 01441640500064439.

[22] Paul A, Chilamkurti N, Daniel A, Rho S. Intelligent Vehicular Networks and Communications: Fundamentals, Architectures and Solutions. Amsterdam: Elsevier;
2017.

[23] Eaton B, Schelling T. Micromotives and Macrobehavior. New York and London: W.W. Norton and Company; 1978.

[24] Joksimovic D, Verhoef E, Bliemer MC, Bovy PH. Different Policy Objectives of the Road-Pricing Problem: A Game-theoretic Approach. London: Edward Elgar Publishing; 2008. http://www-sre.wu.ac.at/ersa/ersaconfs/ersa05/papers/430.pdf [Accessed 2nd June 2021].

[25] Boschma RA, Wenting R. The spatial evolution of the British automobile industry. Papers in Evolutionary Economic Geography. 2004;5(04): 1-23. http:// econ.geo.uu.nl/peeg/peeg0504.pdf [Accessed 2nd June 2021].

[26] Huang W, Zhou J, Xie Y. [Government, Market and people's preference: Experiences and implications of transit development in Los Angeles]. Urban Planning International. 2012;27(06): 107-112. Chinese.

[27] Narahari Y. Game theory and mechanism design. Singapore: World Scientific; 2014.

[28] Duranton G, Turner MA. The fundamental law of road congestion: Evidence from US cities. American Economic Review. 2011;101(6): 2616-2652. doi: 10.1257/ AER.101.6.2616.

[29] Easley D, Kleinberg J. Networks, crowds, and markets: Reasoning about a highly connected world. Significance. 2012;9: 43-44. https://pdfs.semanticscholar.org/ d754/d6b0f8ab6fd30bf72737e4288cc565bfe69c.pdf [Accessed 2nd June 2021].

[30] Eliasson J. A cost-benefit analysis of the Stockholm congestion charging system. Transportation ResearchPartA: Policy and Practice. 2009;43(4): 468-480. doi: 10.1016/ J.TRA.2008.11.014.

[31] Cipriani E, et al. Congestion pricing policies: Design and assessment for the city of Rome, Italy. Transport Policy. 2019;80: 127-135. doi: 10.1016/J.TRANPOL. 2018.10.004.

[32] Phang S, Toh RS. Road congestion pricing in Singapore: 1975 to 2003. Transportation Journal. 2004;43(02): 1625. https://www.jstor.org/stable/20713563 [Accessed 2nd June 2021].

[33] Hau T. Electronic road pricing: Developments in Hong Kong. Journal of Transport Economics and Policy. 1990;24(02): 203-214. https://www.jstor.org/stable/20052918 [Accessed 2nd June 2021].

[34] Livingstone $\mathrm{K}$. The challenge of driving through change: Introducing congestion charging in central London. Planning Theory \& Practice. 2004;5(4): 490498. doi: 10.1080/1464935042000293224.

[35] Leape J. The London congestion charge. Journal of Economic Perspectives. 2006;20(4): 157-176. doi: 10.1257/JEP.20.4.157.

[36] Santos G, Shaffer B. Preliminary results of the London congestion charging scheme. Public Works Management \& Policy. 2004;9(2): 164-181. doi: 10.1177/ $1087724 X 04268569$.

[37] Jansson JO. Public transport policy for central-city travel in the light of recent experiences of congestion charging. Research in Transportation Economics. 2008;22(1): 179-187. doi: 10.1016/J.RETREC.2008.05.027.

[38] Beevers SD, Carslaw DC. The impact of congestion 
charging on vehicle emissions in London. Atmospheric Environment. 2005;39(1): 1-5. doi: 10.1016/J.ATMOSENV.2004.10.001.

[39] Jansson JO. Public transport policy for central-city travel in the light of recent experiences of congestion charging. Research in Transportation Economics. 2008;22(1): 179-187. doi: 10.1016/J.RETREC.2008.05.027.

[40] Eliasson J. Lessons from the congestion charging trial. Transport Policy. 2008;15: 395-404. doi: 10.1016/J. TRANPOL.2008.12.004

[41] Eliasson J, Hugosson M. The Stockholm congestion charging system-An overview of the effects after six months. The Association for European Transport Con- ference, 18-20 September 2006, Strasbourg, France. Melbourne: World Transit Research; 2006. p. 1-22. https://www.worldtransitresearch.info/research/2796/ [Accessed 2nd June 2021].

[42] Börjesson M, Eliasson J, Hamilton C. Why experience changes attitudes to congestion pricing: The case of Gothenburg. Transportation Research Part A: Policy and Practice. 2016;85: 1-16. doi: 10.1016/J. TRA.2015.12.002.

[43] Schaller B. New York City's congestion pricing experience and implications for road pricing acceptance in the United States. Transport Policy. 2010;17(4): 266-273. doi: 10.1016/J.TRANPOL.2010.01.013. 